\title{
Configuración del término "distancia mimética" a través de cinco ejemplos: Ovidio, Platón, Hofmannsthal, Cervantes y Büchner
}

\section{Configuration of the term "mimetic distance" through five examples: Ovid, Plato, Hofmannsthal, Cervantes and Büchner}

\author{
José A. SAntiago SÁncheZ \\ IES Loustau-Valverde \\ litodav@terra.es
}

Recibido: 10/12/2009

Aceptado: 17/01/2011

\section{Resumen}

El concepto de «distancia mimética» se vertebra como hilo conductor de la comunicabilidad artística a través de cinco ejemplos distintos. Por otro lado, se aboga por la preservación de dicho concepto para ilustrar la peligrosa estetización miméticamente apropiadora que caracteriza ciertas filosofías.

Palabras clave: Distancia mimética, arte, autoconocimiento.

\begin{abstract}
The term "mimetic distance" is carried out as a leitmotiv of artistic communication by five well-known different examples. On the other hand, the maintenance of this concept pleads for advice against the dangerous mimetic art that spreads out many philosophical fields.
\end{abstract}

Keywords: Mimetic distance, art, self knowledge. 


\section{Sumario}

1. Primer caso: El mito de Eco y Narciso en Ovidio.

2. Segundo caso: La mimesis en Platón y Aristóteles.

3. Tercer caso: La Carta a Lord Chandos de Hugo von Hofmannsthal.

4. Cuarto caso: el retablo de maese Pedro en el Quijote.

5. Quinto caso: el «arte» en Georg Büchner.

6. Conclusión.

\section{Primer caso: El mito de Eco y Narciso en Ovidio}

$Y$ desde que una tarde nos perdimos Junto a un arroyo, porque tú querías Ser tú solo y ya ido, No nos soltamos nunca de la mano. Pedro Salinas

Como el lector ya sabrá, en la mitología griega, Narciso (en griego Nó $\rho \kappa \iota \sigma \sigma o \varsigma)$ era un orgulloso joven conocido por su gran belleza y acerca de cuya leyenda perduran varias versiones. La más célebre, y la primera en combinar las historias de Narciso y Eco es la de Ovidio. Según esta, tanto doncellas como muchachos se enamoraban de Narciso a causa de su hermosura, mas él rechazaba altanero sus insinuaciones. Eco, por el contrario, es caracterizada en el mito ovidiano por su locuacidad frívola hacia los demás. De ello se vale Zeus para que Eco distrajera a su celosa esposa Hera, hablándole incesantemente y así poder consumar clandestinamente una de sus múltiples aventuras amorosas. Es por ello que, al enterarse, Hera castiga a Eco a repetir las últimas palabras de aquello que se le dijera, lo cual produjo que la ninfa se retirara del trato humano y se marchara al campo, donde poco después conoció a Narciso, del que se enamoró.

Pese a que, debido a su atroz castigo, Eco era incapaz de hablar a Narciso de su amor, un día, cuando él estaba caminando por el bosque y se apartó de sus compañeros, Eco pudo repetir las últimas palabras que Narciso pronunciaba mientras los buscaba, y que Eco creía que iban dirigidas a ella. Haciendo las palabras suyas y tomándolas como una declaración consentida de amor, Eco se lanzó a los brazos de su enamorado. Pero este se negó cruelmente a aceptarla, por lo que la ninfa, desolada, se ocultó en una cueva y allí se consumió hasta que sólo quedó su voz. Para castigar a Narciso, Némesis, la diosa de la venganza, hizo que se enamorara de su propia imagen reflejada en una fuente. En una contemplación absorta, incapaz de apartarse de su imagen, acabó arrojándose a las aguas. 
Tomando en cuenta los antecedentes de los personajes, se comprueba cómo ambos ya se caracterizan por una hybris, establecida mediante un vicio o exageración inicial de su misma condición. Así, Eco representa lo que para los estoicos constituía un vicio común: la estulticia. Como M. Foucault señala, desde Posidonio hasta Seneca, el stultus es «quien está expuesto a todos los vientos, es decir, quien deja entrar en su mente todas las representaciones que el mundo externo puede ofrecerle». De esta manera, Eco «es incapaz de hacer la división, la discriminatio entre el contenido de esas representaciones y los elementos (...) subjetivos que se mezclan en ella.» El stultus como Eco es «quien no dirige su voluntad hacia una meta precisa y bien establecida» 1 cambiando constantemente de opinión. En este sentido, la stultitia resulta lo contrario al auténtico conocimiento de sí.

En cuanto a Narciso, ya el mismo Ovidio nos colocaba, a través de su relato, en los antecedentes que iban a ser decisivos para su devenir posterior. Su padre, Cefiso, era un río; el nombre de su madre, Liríope, significa «mujer con forma de flor». De este modo podría aplicarse al destino de Narciso el conocido adagio que hiciera célebre Guillaume de Machaut en el s. XIV: ma fin est ma commencement.

El hecho es que, según Ovidio, la profecía sobre el destino de Narciso que Liríope recibe de Tiresias antes de que aquel naciera, anunciaba que este joven alcanzaría larga y madura senectud si no llegaba a conocerse. Así lo presenta Calderón de la Barca en su pieza teatral Eco y Narciso:
Encinta estás. Un garzón
bellísimo has de parir;
una voz y una hermosura
solicitarán su fin,
amando y aborreciendo.
Guárdale de ver y oír.
(Eco y Narciso, 61)

Este fatal conocimiento de sí que predice Tiresias, se opone en principio al proverbio tradicional de la moral griega: $\gamma \nu \omega \theta i ́ \sigma \varepsilon \alpha v \tau o ́ v$, escrito, como se sabe, en el frontispicio del templo de Apolo en Delfos y que constituía una guía filosófica de la conducta humana para obtener la felicidad mediante el ejercicio de la razón. Sin embargo, en el caso de Narciso, este conocimiento de sí tiene más bien que ver con un amor irracional por cuanto imposible, y por ello para el hombre griego, trágico. De hecho, este lema délfico es utilizado por Sócrates en un consejo al ambicioso Alcibíades, que Platón incluye en su Alcibíades mayor (132b), un diálogo de juventud. Dicho lema posee un sentido que, como afirma Foucault, ${ }^{2}$ tiene más que ver

\footnotetext{
1 Foucault, M. La hermeneútica del sujeto. Traducción de Horacio Pons. Madrid: Akal. 2005, p. 133.
}

2 Ibid. 47. 
con el «cuidado de sí», es decir, con el conocimiento de los propios límites del poder de un sujeto para con sus semejantes, que con la introspección individual. A este respecto, algunos comentaristas apuntan a que dicho lema oracular advertía de la seguridad de lo que se iba a preguntar sobre uno mismo cuando se llegaba al tempo de Apolo. Por lo tanto, según Foucault, el «conócete a ti mismo» no significaría un principio abstracto, una suerte de preparación a la sabiduría más elevada que la filosofía que no se dirige a la razón, sino más bien al alma y al espíritu. Todo lo contrario, el «conócete a ti mismo» no podía dejar de inscribirse -como el pensamiento griego clásico- a la persona y no al individuo. Una persona que solo podía conocerse en cuanto que se medía referencialmente (y por tanto, «miméticamente») con sus conciudadanos de la polis y también con los que no lo eran, con los bárbaros o los esclavos. De hecho, y como el lector sabrá, la raíz del término «persona», en efecto, proviene ante todo, del actor que, puesto en escena, para hablar (personare) se coloca delante del rostro una «máscara» (pro-sófon). La persona humana implica, por tanto, un escenario, desde el cual pueda ser contemplada a lo lejos, apotéticamente, a distancia, por las demás personas. De hecho, y como Rodríguez Adrados refiere, el origen del término $\mu \dot{\mu} \mu \eta \sigma \iota \varsigma$ se refería a los rituales arcaicos griegos y significaba la posibilidad de cambiar de personalidad y con ello, de romper o descontextualizar las situaciones normales, asumiendo una identidad distinta. ${ }^{3}$ Se trata del significado prístino que aquí queremos construir a través del concepto de «distancia mimética» en el arte.

De este modo, el conocerse a uno mismo que Sócrates recomienda a Alcibíades, -poderoso heredero de alta alcurnia- se concibe como una mesura frente al «impulso estético» de realizar lo mejor para la polis. Deseo que, en el fondo, y como sostiene Fernando R. Genovés, no tiene nada de altruista, ya que la biografía de Alcibíades - precursor del ambicioso político narcisista- «da cuenta de una de las carreras políticas más trapaceras que se ha tenido noticia en la historia de la humanidad», ${ }^{4}$ una trayectoria pública propia de un sujeto de alta cuna, falsario y corsario, que sintiendo sus planes traicionados por la -para él- canalla ateniense, termina reprobando a su polis y siendo asesinado por un sicario. Es por ello que el consejo que Sócrates le ofrece a partir del lema délfico se dirige justamente a procurarle una saludable, racional y objetiva distancia sobre la misma representación que ante los demás se afanaba en construir -como Eco- a partir del caudaloso y cambiante fluir del río de la opinión ajena. Se trata así de una distancia que también maese Pedro aconseja al trujamán en el cuarto caso a estudiar más adelante: «llaneza, muchacho, no te encumbres, que toda afectación es mala» (Don Quijote, II, 16).

\footnotetext{
3 Rodríguez A. Francisco. Fiesta, comedia y tragedia: sobre los origenes griegos del teatro. Madrid: Alianza, 1983, p. 31 y ss.

4 Rodríguez, Fernando. «La lección de Alcibíades». En El Catoblepas, 42 (2005), [en línea] www.nodulo.org/ec/2005/n042p07.htm $<$ fecha de consulta: 26/03/2010 $>$.
} 
Pero esta noción socrático-délfica del $\gamma v \omega \theta \iota$ $\sigma \varepsilon \alpha v \tau o ́$ v, señala Foucault, ${ }^{5}$ se nos aparece, tras la modernidad, más bien oscura y desdibujada. Y ello justamente debido al progresivo vuelco narcisista de la misma. Así, la experiencia individual basada en la interacción social de la «per-sona» grecolatina queda sustituida en la modernidad, y sobre todo en la posterior época de la imagen mediática, por la contemplación extática y deseosamente posesiva de Narciso. La referencia y su distancia representativa para con las demás personas trágicas quedan evacuadas en virtud de un estético impulso de expresividad. Ello se debe a una hipertrofia moderna de la presencia, manifestada en lo que E. Subirats denomina una «crisis simbólica sin precedentes» 6 debido a que la condición mimética sufre un agotamiento por el que el sujeto se convierte en un espectador, cuya experiencia visual se asemeja a lo que Lacan denominaría una «pulsión escópica», esto es, una apropiación visual del objeto como deseo que se agota en sí misma en tanto éxtasis inmediato y que «otorga al sujeto su condición delegatoria en cuanto propone la construcción de identidad sobre la identificación y la proyección antes que sobre la realización». ${ }^{7}$

De este modo -como señala R. Gubern- no parece casual la genealogía etimológica que identifica Narciso como raíz de narcosis. ${ }^{8}$ Pasividad, descentramiento, externalización y autonegación se perfilan como los caracteres del moderno «individuo espectacular» en tanto espejo de su «yo» mediático. El espectáculo, en tanto que seducción, se revela aquí como una forma de poder: la seducción es entonces la exhibición de la capacidad de satisfacer un deseo y, al mismo tiempo, la promoción de ese deseo. La experiencia de la distancia erótica hacia lo apetente en cuanto objeto mediatizado de cambio toma la forma de una pulsión inmediata y cerrada que exige satisfacción directa. Lo interactivo responde ahora a la forma de lo asimétrico a partir de una relación establecida mediante términos de satisfacción oréctica de consumo. Aplicando lo dicho a la obra de arte, y a través de la tradicional noción de alienación, se comprueba cómo a pesar de su lucha por evadirse de dicha consideración mercantilista en nombre de un «arte por el arte», la cultura moderna se articula sin embargo en el contexto de un placer estéticamente «enriquecedor», diletante y compulsivo, dando lugar a una nueva variante del fetichismo.

$* * *$

\footnotetext{
5 Foucault, 2005, op. cit, (Nota 1) p. 47.

6 Subirats, Eduardo. Linterna mágica. Vanguardia, media y cultura tardomoderna. Madrid: Siruela. 1997, p. 161.

7 Ibid. p. 205.

8 Gubern, Roman. El eros electrónico. Madrid: Taurus, 2000, p. 45.
} 
En la misma cuna de algodones en la que, según nos cuenta la historia, creció Alcibíades parece haberse criado también Narciso, según la otra historia; la de ficción. De hecho, tal y como nos lo narra Ovidio, a consecuencia de la profecía que recibe de Tiresias sobre el futuro de su hijo, Liríope retuvo recluido a Narciso en un lugar montañoso. Cuidó de él, aunque no le permitió salir al exterior, manteniéndolo en una negligente ignorancia acerca de la vida. Cuando las circunstancias le fuerzan a trasladarse al valle, ya que Anteo la ha llevado allí en contra de su voluntad, Liríope acepta lo inevitable, aunque ejerce una estricta vigilancia sobre el hijo. Así entonces, Narciso se configura como un muchacho sin apenas contacto con el mundo de las personas, criado bajo el cuidado de una madre sobreprotectora. Esto muestra la radical diferencia respecto del otro personaje de mito: mientras que la chismosa Eco se presta a la heteroclitidad de opiniones de la gente, buscando su valía a través de los demás, Narciso se muestra ante los otros autosuficiente y esquivamente engreído, debido a una educación excesivamente dedicada. De ello van a darse dos personalidades distintas: por un lado la estulticia de Eco, deseosa de satisfacerse a través de las palabras de los demás. Por otro, la soberbia de Narciso, monológico e incapaz de abrirse a alteridad que no sea la de su propia imagen especular. Ambos resultan castigados como operación responsable y consecuente a su viciada personalidad: Eco desde la imposibilidad de rebasar su metalingüismo mimético desde ella misma. Narciso desde la incapacidad de rebasar su meta-especularidad desde el otro. Así pues, Eco es castigada a sufrir una práctica aporética y metalingüística de su habla, la cual solo puede solucionarse a través de la repetición mimética a través de otro, mediante el cual su decir apunte $(\sigma \eta-\mu \alpha \boldsymbol{v} \omega)$ significativamente hacia esa misma otredad deseante. De esta manera, el otro, es decir, Narciso, se convierte a sí mismo no solo en el mediador, sino en el cumplidor de la apropiación comunicativa, cosa que, mediante su propio castigo, es decir, su monológica apropiación mimética en el espejo del agua, es incapaz de llevar a cabo

Se trata, por tanto, de dos límites comunicativos antinómicos. El que resulta del autos y el propio del heteros o del alius, pero desde caminos ilocucionariamente contrarios. En el caso de Narciso, su egocentrismo se castiga con la esclava contemplación de sí mismo como un siempre desposeído otro. En el caso de Eco, su frívolo y devaluado Gerede con la pura heteroglosia por la que la ninfa confiere el verdadero valor idiomático de su palabra mediante la repetición de las de su amado, haciéndolas imposiblemente suyas. La permanente e infranqueable distancia entre ambos personajes muestra al mismo tiempo la coincidencia en la inaprehensibilidad del objeto deseado. Desde la mirada en el personaje de Narciso, desde la palabra en Eco.

Pero además, y como también se ha señalado, el ineluctable incumplimiento amoroso de los propios personajes aparece también de un modo contrario: en Narciso como la imposibilidad de convertirse a sí mismo en otro amado. En el caso 
de Eco, como la incapacidad de tomarse autónomamente en tanto sujeto amante. La aporía se manifiesta en tanto que Narciso no puede salir de sí y Eco no puede entregarse a otro. Narciso es incapaz de contemplar nada que no sea sobre sí mismo y Eco es incapaz de proyectar los signos huérfanos de semantema que salen de su boca. Ninguno accede a la apropiación: quedan limitados a un ver-oír desde una distancia ineluctable que ya estaba requerida a priori en cada personaje.

Se comprueba así como la noción de «mimesis» queda inscrita a partir de una paradoja de la distancia similar a la que se ha percibido entre Eco y Narciso. De este modo, el balanceo de distancias permite calificar la mimesis a partir de una visión de la verdad más propiamente metafórica, es decir, establecida performativamente a partir de la fluctuación de distancias entre los términos bipolarizados («sensibleinteligible» o «arte-naturaleza») y no tanto hipostasiada o identificativa, propia de un modo más propiamente representativista o expresivista. Así lo señala el poeta argentino R. Juarroz en un poema:

El mundo es el segundo término

de una metáfora incompleta,

una comparación

cuyo primer elemento se ha perdido.

¿Dónde está lo que era como el mundo?

¿Se fugo de la frase

o lo borramos?

¿O acaso la metáfora

estuvo siempre trunca?

Los truncados personajes de Narciso y Eco vehiculan la concepción de la mimesis desde dos sentidos que ya se han mostrado contrarios, aunque tocantes. En el caso de Narciso, se produce una duplicidad identitaria que contempla alienada la metaforización truncada a posteriori a partir de la mismidad. En el caso de Eco, la radicalización de su heteromatismo lingüístico a través del otro permite metaforizar

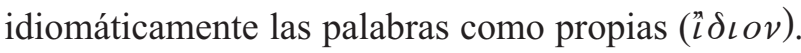

- ¿Hay alguien aquí?

- Aquí (respondió Eco)

- ¿Por qué huyes de mí?

- Huyes de mí (respondió). Eco salió de su escondite y corrió a abrazar a Narciso.

Pero él la apartó bruscamente

9 Juarroz, Roberto. Poesía vertical 1958-1982. Buenos Aires: Emecé, 1995, p. 189. 
- ¡Moriré antes de que puedas yacer conmigo!

- Yace conmigo. Suplicó Eco.

(Metamorfosis, III)

De este modo, la mimesis no toma en el mito ovidiano la forma de una mera repetición representativista, sino que supone el decisivo paso para situarse «entre» ambos términos irrebasables y paradójicamente referenciales: Eco y Narciso. El encuentro de dos soledades del que Rilke hablara en sus Cartas a un joven poeta ${ }^{10}$ ilustra la imposibilidad de la vía unitiva en el mito. Por ello, esa distancia es justamente la que fundamenta el status mismo de la mimesis. De manera que, a través del mito, se presenta en cada personaje una relación orientada constitutivamente hacia algo otro perteneciente a una clase autotética de referencia o de otras clases colindantes y, al mismo tiempo, alotética, ya que entre quien habla y quien escucha se desarrolla, por rotación o inversión, una relación que pretende alcanzar una estructura simétrica desde el momento en que Narciso toma a su imagen como su amado y Eco a Narciso como su amante. De ahí el movimiento se convierte en transitivo, y posteriormente reflexivo. La distancia imposible de someterse a una representatividad ordinaria, resulta entonces la incomensurabilidad misma por la que Eco y Narciso se identifican.

Así pues, la potencial conexividad comunicativa entre Eco y Narciso resulta aquello que los distingue irremisiblemente. En el aspecto comunicativo ello significa, para G. Bueno11 que la relación de igualdad, fundada en el lenguaje, que define a los comunicantes (ya sea en el plano ordinario o artístico) como un subconjunto alotético de la clase de los hombres, «es una relación de equivalencia capaz de introducir una partición de esta clase en partes disyuntas, y por tanto, incomunicables entre sí a través de sus hablas». Es decir, que el hecho de establecer una relación simétrica desde la misma dimensión lingüística es garantía tanto del éxito de su interacción comunicativa como de su fracaso. Como sucede en el caso del mito, la relación de equivalencia mimética que el lenguaje pueda implicar (y no ya de igualdad, unidad, comunidad o nacionalidad) entre ellas, es tanto o más relevante como su radical separación, por la cual Eco y Narciso quedan separados, y asimismo unidos. En el mito no existe «un lenguaje», propio, sino «los lenguajes» los cuales, justamente por su equivalencia formal, resultan recíprocamente inconexos y se hacen idiomáticos, es decir, a-propiados ( $\stackrel{n}{\iota} \delta\llcorner o v)$. De este modo, la «identidad» de cada uno de los personajes resulta construida más por diferenciación que por igualitarismo, pero siempre mediante una distancia mimética entendida de modo metafórico, esto es, no simétrico. Esta distancia que imposibilita la asunción total del

10 Rilke, Rainer M. Cartas a un joven poeta. Traducción de José M. Valverde. Madrid: Alianza. 1999, p. 59.

11 Bueno, Gustavo. Televisión: Apariencia y Verdad. Barcelona: Gedisa. 2000, p. 59. 
otro (ya sea autotético en Narciso o alotético en Eco) constituye en el mito justamente la topología e identidad reflexiva de los personajes. La cuestión, como insiste Bueno, no es por tanto «la de demostrar el hecho de las diferencias, en nombre de la igualdad, sino por el contrario demostrar la igualdad a partir del hecho de las diferencias» 12 . No en vano aparece así en la narración bíblica, a partir del celebérrimo mito de la Torre de Babel (Gen. 11, 1-9), el cual muestra, aplicado al lenguaje, que la comunicatividad nunca es singular, sino plural. Por ello el «don» de las lenguas aparece como castigo divino impuesto a los humanos por una hybris similar a la que el autólogo Narciso y la heteróloga Eco cometieron ante los dioses. Este aspecto descalabrado y sufriente del «Lenguaje» como «idiomas» en la descripción de Eco y Narciso resulta decisivo en su identificación misma a través del otro. De este modo, es el desclasamiento de la «Lengua» común lo que permite fundar el «idioma» propio y per-sonal de modo mimético, tal y como lo hemos analizado anteriormente. Solo así sucede, en consecuencia, lo que el lingüística ruso M. Bajtin13 señalara: «el hombre no dispone de un territorio soberano, sino que está, todo él y siempre, sobre la frontera, mirando al fondo de sí mismo, el hombre encuentra los ojos del otro o ve con los ojos del otro». Pero también, de este modo, la distancia mimética convierte el conocimiento en reconocimiento, según la tesis que formulara Platón en el Teeteto: «el pensamiento es el diálogo del alma consigo misma» (Teeteto 195a). La distancia mimética postula la recepción comunicativa no de modo transitivamente apropiado, sino atributivamente identificado.

Así también conviene aclarar que justamente a través de los modos distintos y limítrofes de su hablar, Eco y Narciso muestran que el lenguaje no sólo es un medio de trasmitir información (función referencial), ya sea sobre el mundo o sobre los estados emotivos del hablante (función conativa), o un medio para provocar dichos estados en el oyente (función emotiva), sino que se funda más precisamente desde su interacción con el otro. Así se pronuncia Xabier Zubiri en cuanto a lo dicho:

«Yo» no es la realidad del sujeto, sino justamente al revés: es la realidad del sujeto la que tiene como propiedad, digámoslo así, el ser un «yo». Ser «yo» es un momento, -no el único ni el primario- de la realidad del sujeto en acto segundo, operativamente; no es un momento entitativo. La realidad del sujeto está allende el yo. ${ }^{14}$

Pero esta interacción debe justamente preservar una distancia necesaria para que suceda el despliegue de la proyección mimética, por la que emisor y receptor, en su idiomática situabilidad referencial, se identifican al tiempo emisora y recepti-

\footnotetext{
12 Ibid.

13 Bajtin, Mijail. Teoría y estética de la novela. Trad. de Helena Kriukova y Vicente Cazcarra. Madrid. Taurus. 1989, p. 167.

14 Zubiri, Xabier. Sobre la esencia. Madrid: Alianza. 1985, p. 380.
} 
vamente, y viceversa. Así lo simbolizan Eco y Narciso. Del mismo modo habla la poetisa argentina A. Pizarnik en unos versos que nos recordarían la contemplación de Narciso: «recibe de mí lo que eres tú». 15

Sin embargo, la distancia puede tomarse de un modo más irreductible e irrebasable. En este sentido, emisor y receptor (o sujeto y objeto) asumen distantes $-\mathrm{y}$ justo por ello deseantes- esa misma irrebasabilidad desapropiadora, en la asunción del lugar mismo de cada uno de ellos que permite situar una primaria incomensurabilidad mimética. Por ello otra gran poetisa como la griega Safo habría dicho, con versos que recordarían a Eco: «en cuanto te diviso un instante, no me es ya posible articular palabra, sino que mi lengua se desgaja». 16

\section{Segundo caso. La mimesis en Platón}

En el tercer libro de La República, Platón establece de un modo sucinto una distinción entre el concepto de «diégesis» $(\delta\llcorner\eta \dot{\eta} \eta \eta / \varsigma)$ o narración, y el concepto de

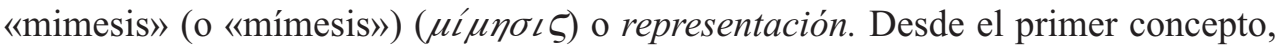
el poeta habla por sí mismo y, debido a esto, el lugar del relator se posiciona frente a los hechos a relatar, logrando así una «distancia» entre el poeta y lo contado por él mismo. En el segundo, el poeta cede la palabra a los personajes, creando una cercanía que, sin embargo, se antoja ilusoria. De este modo, Platón esboza una diferencia que posteriormente constituirá la famosa condena de la poesía, y que ocupará buena parte del décimo libro de La República. Al comienzo de dicho libro, Sócrates presenta el tema de la «poesía puramente imitativa» ( $\mu$ í $\mu \eta \sigma \iota \varsigma)$ como lo por tratar allí, una vez que se ha analizado en capítulos anteriores el estudio de las partes del alma más bajas y más elevadas. Ello es debido, según el personaje Sócrates, a que este tipo de poesía corrompe el espíritu de los «que no disponen del antídoto conveniente». (República 559b). Este antídoto supone en Platón una superposición de los dictados racionales del alma para con los concupiscibles y, sobre todo, irascibles. Es por ello que Sócrates, preguntado por su interlocutor, señala que los que tienen una visión más débil («distante» podríamos decir) son aquellos que pueden hablar con más propiedad sobre lo que es la mimesis «antes que los que la tienen muy penetrante» (La República 596a).

¿A qué se refiere Platón con dicha visión penetrante? O mejor, ¿a quiénes se dirige con dicha descripción? Probablemente a los sofistas, sagaces maestros de la palabra que disuaden con su discurso los ánimos de sus oyentes, y que se convier-

15 Pizarnik, Alejandra: Poesía. Madrid, El País. 2009, p. 112.

16 Safo. Poemas y testimonios. Traducción de Aurora Luque. Madrid: El Acantilado. 2004, p. 58. 
ten en grandes enemigos de sus planes para la polis. No en vano E. Bréhier ${ }^{17}$ señala cómo en la Grecia de aquel entonces, el filósofo se definía sobre todo por su relación y sus diferencias con el orador, el sofista y el político. El carácter sicofante $(\psi v \chi \dot{\eta}-\phi \alpha \dot{\nu} \omega)$ de la sofística es el que Platón atribuye también a la poesía mimética, pues presenta en su artificio una apariencia $(\phi \alpha \hat{\boldsymbol{\nu}} \omega)$ doblemente imitativa al crear una copia narrativa de la realidad, la cual es asimismo copia imperfecta de las ideas. Pero lo que Platón repudia de la poesía imitativa no es en el carácter mimético de ésta, sino la artisticidad tomada como real a través de la volubilidad del ánimo $\left(\psi v \chi \eta^{\prime}\right)$ que en los oyentes de dicha poesía se produce mediante la escucha o la lectura de una palabra doblemente imitativa con respecto a la verdad. Platón no deja de percibir un peligro para la República si aquellos que estetizan con emociones o sentimientos una realidad vicaria, al mismo tiempo la «humanizan» a través de las facultades irascibles del alma, rompiendo con la distancia que existe entre el mundo de las cosas sensibles y la Verdad en la que éstas participan.

(...) en la misma forma, el poeta, sin otro talento que el de imitar, sabe, con un barniz de palabras y expresiones figuradas dar tan bien a cada arte los colores que le convienen (...) que convence a los que escuchan y que juzgan solo por los versos que está perfectamente instruido en las cosas de que habla. (República 601a)

Es por ello que la furibunda crítica a la $\mu \iota ́ \mu \eta \sigma \iota \varsigma$ adquiera un fuerte sabor moral, pues como el propio Sócrates afirma en otro lugar, «es fácil representar los caracteres apasionados del alma para agradar a la multitud» (República 605a). Mediante la accesible y subjetivamente construida comunicabilidad que los poetas miméticos o los sofistas extienden en la sociedad, la estetización arti-ficial por cuanto artí-stica, se apodera de lo sensible -en sí mismo una mimesis de las ideas-y confiere valor de verdad a lo que, sin embargo se encuentra «a triple distancia del ser» (República 599a). En ello se demuestra que esta distancia dialéctica, participativa, parusíaca y mimética propia de los dos mundos platónicos resulta decisiva en su pensamiento. ${ }^{18}$ Así lo señala Cervantes por medio de Don Quijote, otro de los ejemplos que trataremos brevemente con posterioridad. Se trata de un pasaje de sobras conocido:

17 Bréhier, Emile. Historia de la filosofía, I. Traducción de Juan Antonio Pérez Millán y M ${ }^{a}$ Dolores Morán. Madrid: Tecnos. 1988, p. 128.

18 Otro gran autor griego que trata el concepto de mimesis es, como se sabrá, Aristóteles. Sin embargo, éste, de entrada, no la concibe en el mismo sentido moral que lo hace su maestro Platón. En Aristóteles, su empleo se constriñe únicamente a las ciencias poiéticas, excluyendo por tanto las teóricas y las prácticas. A partir del agudo análisis de Paul Ricoeur, se comprueba cómo lo que caracteriza a la mimesis aristotélica no es la relación de participación o semejanza, al igual que en Platón, sino 
La poesía, señor hidalgo, a mi parecer, es como una doncella tierna y de poca edad, y en todo estremo hermosa, (...) pero esta tal doncella no quiere ser manoseada, ni traída por las calles, ni publicada por las esquinas de las plazas ni por los rincones de los palacios. Ella es hecha de una alquimia de tal virtud, que quien la sabe tratar la volverá en oro purísimo de inestimable precio; hala de tener, el que la tuviere, a raya, no dejándola correr en torpes sátiras ni en desalmados sonetos; no ha de ser vendible en ninguna manera, si ya no fuere en poemas heroicos, en lamentables tragedias, o en comedias alegres y artificiosas; no se ha de dejar tratar de los truhanes, ni del ignorante vulgo, incapaz de conocer ni estimar los tesoros que en ella se encierran. Y no penséis, señor, que yo llamo aquí vulgo solamente a la gente plebeya y humilde; que todo aquel que no sabe, aunque sea señor y príncipe, puede y debe entrar en número de vulgo. (Don Quijote, II, 16)

\section{Tercer caso: La Carta a Lord Chandos de Hugo von Hofmannsthal}

«Haciéndonos Eco» de los versos de Safo, pasamos a otro de los ejemplos a tratar: la notable Carta de Lord Chandos, (1902) de Hugo von Hofmannstahl, donde se puede comprobar de nuevo ese mismo desgajamiento de la lengua, a partir de la distancia mimética que venimos tratando. En ella, el remitente de dicha carta, al parecer un poeta, confiesa al canciller Francis Bacon -a la sazón su destinatariohaber experimentado una profunda crisis, según la cual el autor ha perdido por completo «la capacidad de pensar o hablar coherentemente sobre ninguna cosa». ${ }^{19}$ Lord Chandos confiesa una suerte de imposibilidad de abarcar en conceptos la realidad que le rodea. Su «cercanía» simpatética con los objetos provocan en el poeta sensaciones como esta: «las palabras aisladas flotan alrededor de mí; cuajan en ojos que me miran fijamente y de los que no puedo apartar la vista: son remolinos a los que me da vértigo asomarme, que giran sin cesar y a través de los cuales se llega al vacío».

el proceso mismo de construcción de la obra. En este sentido, la mimesis se constituye, no en cuanto duplicación de la realidad, sino más bien en tanto recomposición de la misma. De este modo, se produce al tiempo un acercamiento identificativo a la realidad que quiere ser mimetizada, y una distancia del producto mismo con respecto al original. Esta interpretación que expresa la paradoja de la mimesis -la cual no se aleja tanto de la relación platónica entre el mundo sensible y el inteligible- le sirve a Ricoeur para desarrollar la dialéctica cercanía/distancia por la que la primera indica la dimensión referencial y la segunda el momento de la invención-ficción. La diferencia de planteamiento entre ambos filósofos estriba en que para Platón la distancia se concibe de modo crítico-dialéctico, aplicándose hacia un ámbito no puramente artístico y enfatizando más la separación entre los términos. Por el contrario, en Aristóteles, la mimesis toma una función estrictamente poiética (que no meramente artística, sino en general, propia del hacer productivo o industrioso) percibida desde coordenadas más positivas o constructivas. (víd. Ricoeur, Paul. La metáfora viva. Traducción de Agustín Neira. Madrid: Cristiandad. 1980, p. 61 y ss.)

19 Hofmannsthal, Hugo von. La carta de Lord Chandos y otros textos en prosa. Traducción de Antón Dieterich. Barcelona: Alba. 2001, p. 10. 
Lo que Lord Chandos advierte a su confesor es el desmantelamiento del idioma que progresivamente, y poco a poco, fue aprendiendo, pero en el que ahora se muestra incapaz, según el autor, de nombrar términos como «espíritu», «alma» o «cuerpo», al tiempo que lo concreto toma para él un nuevo y sorprendente significado.

Una regadera, un rastrillo abandonado en el campo, un perro tumbado al sol, un cementerio pobre, un lisiado, una granja pequeña, todo eso puede convertirse en el recipiente de mi revelación. Cada uno de esos objetos, y los otros mil similares sobre los que suele vagar un ojo con natural indiferencia, puede de pronto adoptar para mí en cualquier momento, que de ningún modo soy capaz de propiciar, una singularidad sublime y conmovedora; para expresarla todas las palabras me aparecen demasiado pobres. 20

Es por ello que Lord Chandos cae en una convicción que señala al mismo tiempo la constatación de una paradoja y su ineluctable vivencia a partir de entonces: la existencia de una lengua no idiomática con la que nombrar lo inombrable. Una lengua que constituya en sí misma la imposibilidad de todo idioma. Esta desoladora incapacidad de apropiarse lingüísticamente de cada cosa concreta identifica a Lord Chandos con el enamorado Narciso. No en vano, el autor de la carta prosigue instándonos a persistir en su semejanza con el caso narcisista:

Se basaba en no sé qué placer sensual y espiritual: así como el ciervo acosado ansia sumergirse en el agua, ansiaba yo sumergirme en esos cuerpos rutilantes, desnudos, en esas sirenas y dríadas, en esos Narcisos y Proteos, Perseos y Acteones: desaparecer quería en ellos y hablar desde ellos con el don de las lenguas. ${ }^{21}$

En Narciso, así como en Lord Chandos, el deseo conduce infaliblemente a la metamorfosis para con el objeto simpatético. Pero ésta es una metamorfosis imposible. La distancia mimética no puede ser eliminada. Ese es el pesar de Lord Chandos, pero también el de Eco y el de Narciso: cuanto más acercamiento al objeto deseado, menos identificación y más alienación se producen. Al mismo tiempo, esa esperanza de unificación resulta inevitable. Por ello, la «crisis expresiva» que Lord Chandos experimenta toma la forma de una cercanía imposible con las cosas, de una imposibilidad de decir lo mostrado.

De un modo muy similar al Narciso del mito ovidiano, Lord Chandos afirma haberse creído con la ambiciosa y engreída posibilidad de expresar la realidad toda. «Yo quería. Yo quería muchas cosas más» confiesa al canciller Bacon. Así, como él mismo atestigua, su idea había sido la de «reunir una colección de apotegmas, como la que recopiló Julio Cesar». El título que nuestro frustrado poeta pensaba poner a

\footnotetext{
20 Ibid., p. 11.
}

21 Ibid., p. 11. 
tal obra -y esto es lo más curioso-iba a ser nosce te ipsum. «Conócete a ti mismo».

De este modo, el afán apropiador de experiencias enriquecedoras por parte de Lord Chandos quiere desembocar en última instancia en un conocimiento «apropiador» de sí. No obstante, al hacer eso, se encuentra con un afán igualmente iluso por mal fundado: la imposibilidad de desbordar la distancia entre él y las cosas «una lejanía constante,- señala el autor de la carta- siempre dispuesto a retroceder si se me ocurriese correr hacia él para envolverme en el borde de su manto». De este modo, Lord Chandos reconoce la imposibilidad de expresar mediante el lenguaje la sombra de un nogal, la más simple regadera y el agua dentro de ella de este modo: «esa combinación de nimiedades me estremece con tal presencia de lo infinito, me estremece desde las raíces de los pelos hasta los tuétanos del talón de tal manera que desearía prorrumpir en palabras».

Al igual que Narciso o Eco, la cercanía empática con cada objeto de la realidad producía a nuestro protagonista una incapacidad de aprehensión y una mayor e impotente sensación de lejanía.

Y sin embargo y que luego me aparte en silencio de aquel lugar y al cabo de las semanas, cuando divise ese nogal, pase de largo con una esquiva mirada, porque no quiero ahuyentar la postrera sensación de lo maravilloso que flota allí alrededor del tronco, porque no quiero expulsar lo más que terrenales escalofríos que todavía siguen vibrando cerca de allí, alrededor de los arbustos. ${ }^{22}$

Al igual que en el caso de Eco y Narciso, en Lord Chandos tanto esa «sensación de lo maravilloso» como «los más que terrenales escalofríos» nos resultan por momentos una imposición de un «yo» deseoso de conocerse a través de lo otro. Esta concepción de una suerte de «vida superior», como el mismo Lord Chandos lo llama, se percibe también, por ejemplo, en el romanticismo de Keats o de Rilke, y da lugar a toda una inveterada y popular concepción de la poesía desde una nueva visión fundamentalmente lírica. En este sentido, el silencio de Lord Chandos, como el del joven Rimbaud, así como la locura de Hölderlin vienen a constituir el testimonio del mayor intento de romper la distancia mimética con las cosas y, por ello, de destruir la significatividad misma de los signos para que, según los célebres versos de Juan Ramón, la palabra, desde su vaciedad sígnica, se convierta en la cosa misma.

Entonces siento como si yo mismo entrase en fermentación, formase pompas, bullese y reluciese. Y el conjunto es una especie de pensar febril, pero un pensar con un material que es más directo, líquido y ardiente que las palabras. Son también remolinos, pero no parecen conducir, como los remolinos del lenguaje, a un fondo sin límite sino, de algún modo, a mí mismo y al más profundo seno de la paz.

22 Ibid., p. 12. 
Y así, la carta casi concluye del siguiente modo:

porque la lengua, en que tal vez me estaría dado no sólo escribir sino también pensar, no es ni el latín, ni el inglés, ni el italiano, ni el español, sino una lengua de cuyas palabras no conozco ni un sola, una lengua en la que me hablan las cosas mudas y en la que quizá un día, en la tumba, rendiré cuentas ante un juez desconocido. 23

Este «fondo sin límite» de las cosas del que habla Lord Chandos se identifica con el fondo proteico del río en el que Narciso se contempla. Y por ello, toda esta verdadera y auténtica revelación de lo real tal y como es, se revierte en una metáfora, por la cual, según el propio autor nos señala, dicho «estallido puro de lo real» no le conduce... sino a él mismo. Y sin embargo, al igual que en Narciso, a partir del castigo divino, el conocimiento de sí mismo resulta para Lord Chandos inalcanzable. «El rostro absoluto, y la firmeza mentida del espejo», canta J. Lezama Lima ${ }^{24}$ en su Muerte de Narciso. De este modo, la «metáfora trunca» de la realidad en Narciso y Lord Chandos forzaría o viciaría, a este respecto, la distancia proyectiva de esta metáfora, al tomar el término de lo real desde otro término -el «yo» quecomo se citaba en el poema de Juarroz, se «fugó de la frase» porque nunca estuvo. La imposibilidad que Lord Chados, en definitiva constata, es la inaprehensibilidad -desde una excesiva cercanía- que el yo lírico impone al objeto para apropiárselo miméticamente. Pero la consecuencia resulta la misma que la de Narciso ante el espejo. Así lo señala $\mathrm{O}$. Paz en un poema:

Frente a los fuegos fatuos del espejo

Mi ser es pira y es ceniza,

Respira y es ceniza,

$\mathrm{Y}$ ardo y me quemo y resplandezco y miento

Un yo que empuña, muerto,

Una daga de humo que le finge

$\mathrm{La}$ evidencia de sangre de la herida,

$\mathrm{Y}$ un yo, mi yo penúltimo,

Que sólo pide olvido, sombra, nada,

Final mentira que lo enciende y quema.

De una máscara a otra

Hay siempre un yo penúltimo que pide.

Y me hundo en mí mismo y no me toco. 25

23 Ibid.. p. 12.

24 Lezama L. José. Poesía. Madrid. Cátedra. 2000, p. 75.

25 Paz. Octavio. Libertad bajo palabra. Madrid: Cátedra. 1998, p. 78. 


\section{Cuarto caso: el retablo de maese Pedro en el Quijote}

El caso que nos ocupa en cuarto lugar se sitúa en el contexto del primer siglo XVII, el siglo del Barroco. Se trata de la célebre historia del retablo de maese Pedro, narrada en los capítulos XXV y XXVI de la segunda parte del Quijote, la cual fue publicada, como el lector bien sabrá, en 1615. Así pues, se trata de un contexto muy distinto al tardorromanticismo de Hofmannstahl, y, por ello mismo, de un caso, y en general, de una obra literaria en la que el papel de la mimesis y su distancia resultan tan contrarios como la contrariedad misma de los personajes de Narciso y Eco.

El lenguaje romántico se concibe como manifestación poética de un absoluto que, desde el presente, emerge como síntesis en el individuo, al igual que Narciso (o Lord Chandos), extasiado ante una realidad cambiante que no constituye sino su propia proyección yoica y que nunca puede ser aprehendida. De este modo, el papel del artista es trágico por antonomasia, pues la distancia mimética entre realidad y su representación (entendida en muchos casos desde la dicotomía entre "vida» y «arte») ansía ser anulada para unir ambos ámbitos. En el Barroco, sin embargo, el movimiento es muy otro: el arte constituye un ámbito separado de la realidad, aunque equiparable a cualquier otro hacer poiético o industrioso. S. Sarduy define el Barroco como el arte simulativo por antonomasia, «disfrazante, de superposición artificial y ocultación, como derramamiento sígnico, proliferante e hipertélico». ${ }^{26}$ La mimesis alotética permite, de este modo, asimilar en parte el movimiento barroco con la naturaleza del personaje de Eco. Siguiendo a Sarduy, el barroco se describiría entonces como «una hipertrofia que va más allá de sus fines, una impulsión letal de suplemento, de simulacro y de fasto». ${ }^{27}$ Esta férrea y objetiva preservación barroca de la distancia mimética hace que Jorge L. Borges, por ejemplo, desconfiara de la obra barroca como forma pura, concebida en tanto objeto precioso, indiferente y apartado de las realidades del mundo. De ahí arranca en parte la crítica tradicional al Barroco, entendido como un período de agotamiento de las últimas posibilidades del arte, en el cual éste sólo remite a su propia y vicaria realidad. Así, el Barroco se mostraría como decadencia de todo periodo artístico, una leyenda en sí misma ya asaz decadente, una hipotiposis desesperada y metaestética. Toda vez que el propio Borges 28 narrara en su famoso cuento -de espíritu muy barroco a este respecto- titulado Parábola de Palacio, la historia de un poeta, llamado por un poderoso emperador, el cual mediante una composición, reproduce el maravilloso palacio de su amo, de tal manera que logra identificarlo totalmente con él, por lo que el poeta es condenado a muerte. Se trata -decimos- del mismo Borges que señala en

\footnotetext{
26 Sarduy, Severo. Barroco. Ensayos generales sobre el barroco. Buenos Aires: Sudamericana. 1974, p. 61.

27 Ibid.

28 Borges, Jorge Luis. Obras Completas vol. II. Buenos Aires: Emecé. 1999, p. 179.
} 
un poema, titulado justamente Arte poética:

A veces en las tardes, una cara

Nos mira desde el fondo de un espejo

El arte debe ser como ese espejo

Que nos revela nuestra propia cara. ${ }^{29}$

La obra donde se incardina este tercer caso a estudiar, El ingenioso hidalgo don Quijote de la Mancha, responde, como señala Alberto Mangel ${ }^{30}$ a un fabuloso juego de espejos donde el autor del texto se convierte en personaje y los personajes a su vez, se incardinan en historias dentro de otras historias. A este respecto, el Quijote se constituye en una obra típica de la cosmovisión barroca, en la que los continuos espejismos entre ficción y realidad no permiten distinguir lo que es arte de lo que es real. Por ello, y como señala Eugenio D'Ors, la mimesis barroca -al igual que la romántica- parte de la convicción del Paraíso Perdido. Pero lo hace, al contrario que aquél, manteniendo siempre la distancia escópica, y proponiendo un juego -como es el caso del Quijote- y no una búsqueda absoluta e intemporal de cada objeto desde el yo. De este modo, la obra cervantina se sitúa en una finitud topológica que juega a mirar y asimismo, a mirarse proteicamente. No en vano, una de las metáforas literarias más pregnantes del Barroco resulta ser la del espejo. Pero en el caso de El Quijote, se trata de un espejo heterólogo el cual, a partir de una imagen alotética, el sujeto, como Eco, se identifica en lo otro desde su mimética y heteróclita repetibilidad. Por ello, El Quijote se toma como un juego, es decir, una creación artística separada de la realidad, de sus normas y sus contenidos, aunque, por ello mismo, miméticamente relacionada con ella. El juego sitúa el arte en el espejo de la realidad y de la vida, no en su lugar. Y lo hace sin esa a menudo solemnidad del absoluto idealista y romántico.

Pues bien, en la historia que nos ocupa al caso -y que fuera musicalizada, como se sabe, por Manuel de Falla en 1924- el hidalgo manchego y su fiel escudero se encuentran ante el retablo del titiritero maese Pedro. Allí se detienen a contemplar una representación en la que se cuenta la historia de Melisendra, esposa de don Gayferos, a quien tenía cautiva el rey moro Marsilio, la liberación de la misma por su marido y la persecución por parte de los moros. En un punto de la representación, don Quijote -observando el desarrollo de los acontecimientos-intenta salvar a los fugitivos y, dejándose llevar por su condición de desfacedor de entuertos, se lanza al socorro de Melisendra ante el asombro de Maese Pedro y el resto de los espectadores, destrozando así todo el retablo.

29 Ibid.. p. 221.

30 Mangel, Alberto. «Don Quijote, autor de Cervantes». En Estudios públicos, 100 (2005), p. 44. 
Planteada la historia de este modo, y para el lector que no la conociere, cabría pensar que don Quijote se ha dejado engañar de nuevo. Sin embargo, en varios momentos de la representación, nuestro hidalgo prorrumpe en continuas quejas, debido a las incongruencias de la propia narración. Así, por ejemplo, cuando rey Marsilio manda tocar las campanas de todas las mezquitas al ver regresar a su hija Melisendra, don Quijote señala que «entre moros no se usan campanas, sino atabales, y un género de dulzainas que parecen nuestras chirimías; y esto de sonar campanas en Sansueña sin duda que es un gran disparate» (Don Quijote II, 26). Nuestro hidalgo, por consiguiente, no es un espectador fácilmente manipulable, pero su locura le impide medir la distancia entre ficción y realidad, creyendo que en verdad la pobre Melisendra necesita ser socorrida. Se puede decir entonces que un espectador como don Quijote toma la obra de un modo tan cercano y real, que llega a destruirla, eliminando de este modo, su carácter artístico y en definitiva, su «mentira» mimética. Por otro lado, la acción de don Quijote sería imposible desde el punto de vista del propio autor del drama, el cual necesariamente debe cumplir con su autoría. De este modo, Don Quijote, en tanto receptor de la obra autoral, se convierte en el espectador en el que ningún autor jamás podría convertirse si no fuera negándose a sí mismo y a su propia condición. Es por ello que C. Presberg señala que «en parte, don Quijote representa la reducto ab absurdum de los lectores y textos que fútilmente asemejan la "verdad" no con una búsqueda, sino con un cierto, formulista y apriorístico cierre.»31

Al mismo tiempo, el personaje cervantino cumple con la destrucción de la obra dentro de la obra, llevándola hasta su máxima verdad y haciendo del proceso de autoría y recepción artística, es decir, de autor y lector, un tópos dentro de la contextualidad narrativa. «En un sentido, se ha jugado con nosotros. - señala H. Percasse nos ha manipulado. Todos nos hacemos, entonces, actores en un tipo de "tercer teatro", donde cada uno de nosotros es una figura más de carne y hueso».32 El Cervantes-autor parece vislumbrar ese umbral en el que la obra en definitiva no puede remitir más que a ella misma. Al convertir la historia en una narración dentro de otra narración, al introducir la propia primera parte del libro dentro de la segunda, al jugar mediante los apócrifos con la propia autoría introduciendo a «personajes» que se convierten en las «personas» que han escrito o contado la historia como Cide Hamete Benengeli o el propio Avellaneda, Cervantes, al igual que don Quijote, no rompe ni anula la representatividad, sino que más bien la invierte espejando las dimensiones de lo artificial y lo real, y justificando así el artificio desde el artificio mismo. La metáfora mecanicista del mundo como reloj, o del mundo como

31 Presberg, Charles D. «"Yo sé quién soy": Don Quixote, Don Diego de Miranda and the Paradox of Self-Knowledge». En Cervantes: Bulletin of the Cervantes Society of America, 142 (1994), p. 53.

32 Percas, Helena de. Cervantes y su concepto del arte: Estudio crítico de algunos aspectos y episodios del "Quijote", vol. II. Madrid, Gredos, (1975), p. 594. 
escenario (All the world's a stage) ${ }^{33}$ vehiculan la misma cosmovisión miméticamente especular del Barroco:

en la comedia y trato deste mundo, [hay]... unos [que] hacen los emperadores, otros los pontífices, y, finalmente, [hay] todas cuantas figuras [que] se pueden introducir en una comedia; pero en llegando al fin... a todos les quita la muerte las ropas que los diferenciaban, y quedan iguales en la sepultura. (Don Quijote, II, 12)

Don Quijote -como Eco- no puede, en definitiva, contemplar lo mostrado más que desde su propia y alterada condición. Por ello, al querer incidir en ello y aprehenderlo, lo difumina o lo destruye. En una obra como El Quijote donde su propio arte se desarrolla a partir de un permanente proceso de autoidentificación, don Quijote se muestra - sin embargo- como el único que cumple la sentencia délfica y se conoce a sí mismo. "Yo sé quien soy» le dice a un labrador algunos capítulos antes de vivir la aventura de maese Pedro (Don Quijote II, 5). Don Quijote, por tanto, es el único que invierte -mediante el acto de romper el retablo- el proceso narcisista de autoexamen y autorreflexión mimética. Y lo hace a través de un juego de espejos autorales en los que consiste gran parte de la obra cervantina y en el cual el propio hidalgo se convierte en personaje dentro de su propia historia.

En este sentido, el espejo en el que don Quijote se refleja al contemplar la trama del retablo, o la de su propia historia a través de Cide Hamete, no es distinto al de su vida de caballero andante. Es por ello, advierte con pena Maese Pedro a Don Quijote, que los títeres «no son verdaderos moros, sino unas figurillas de pasta» (Don Quijote II, 26). Sin embargo, Cervantes parece mostrarnos aquí que la honestidad de don Quijote en tanto espectador comprometido consigo mismo, y por tanto, con la obra artística, no le permite justamente distinguir entre ficción y realidad, entre arte y vida. «Si no me hallara yo aquí presente- señala el valiente hidalgo-qué fuera del buen don Gaiferos y de la hermosa Melisendra; a buen seguro que ésta fuera ya la hora que los hubieran alcanzado estos canes.» El compromiso con el arte en tanto dimensión política, rememorante y en definitiva, vital, ¿no implicaría en definitiva el cumplimiento mismo a partir de su disolución artística? E.T.A. Hoffman $^{34}$ afirmará dos siglos después, en 1814, que hay que romper la ilusión de acercar el teatro al espectador y hacer que se implique. El escritor alemán nos sitúa en el caso de una representación teatral; entonces, justo en el momento de mayor emoción, se deja caer el telón, para de este modo, soslayar su «gravedad» y mostrar de modo abrupto que todo es una farsa. Se trata, según Hoffman, de hacer caer los

\footnotetext{
33 Shakespeare. W. Como gustéis, II, 7.

34 Hoffman, E.T.A. Puntos de vista y consideraciones del Gatomurr sobre la vida en sus aspectos y biografía fragmentada del maestro de capilla Johannes Kreisler en hojas de borrador casualmente incluidas. Traducción de Eustaquio Barjau y Marisa Siguan. Valencia, Pre-textos. 1998, p. 30.
} 
límites para así acentuar las posiciones. Asimismo para don Quijote -aquél que se conoce a sí mismo- la apropiadora y falsaria artisticidad especular queda desmantelada. Por ello, en la obra Cervantina, como señala Presberg, 35 se llama constantemente a la contemplación personal en cuanto acción auto-reflexiva y autoidentificadora a partir del mantenimiento de la distancia mimética entre ficción y realidad. O entre arte y vida. Cuando dicha distancia queda eliminada, es decir cuando don Quijote recupera moribundo su cordura, la que Cervantes insiste en presentar como «verdadera historia» del Quijote, como la del Retablo, o la de Cide Hamete, alcanza su status con respecto a una realidad miméticamente distante. Cae definitivamente el telón. Todo era un artificio. Es el fin.

\section{Quinto caso: el «arte» en Georg Büchner}

Al inicio de la historia cervantina que hemos mencionado, maese Pedro se presenta en la posada, con «el mono adivino y el retablo de la libertad de Melisendra» (Don Quijote II, 25). A este respecto resulta interesante destacar que el mono representa un ejemplo emblemático de la mimesis en la creación literaria. De este modo, maese Pedro simboliza de entrada al titiritero que lleva su «arte» con las facultades divinas de la adivinación (así como sucedía en el oráculo socrático-délfico) para el regocijo de los espectadores. Ese «arte» simiesco nos es presentado por el dramaturgo alemán G. Büchner, allá por el año 1835, de un modo muy similar en su única obra en prosa, Lenz: «¡Damas! ¡Caballeros! Vean ustedes la criatura, tal y como Dios la formó: nada, nada de nada. Vean ahora el arte: anda derecho, lleva levita y pantalón, lleva un sable».36

Esta caricaturización simiesca del arte termina en el episodio cervantino con la destrucción del retablo del «artista» maese Pedro. Y lo hace a través de la reacción humanamente alocada del más entregado de los espectadores, el cual aniquila, en razón del arte, al arte mismo. Así se manifiesta en otra obra de Büchner, La muerte de Danton (III, 3) donde aparece un motivo muy similar:

Os digo que si no se les da todo en insípidas copias, provistas de sus etiquetas: "Teatros", "Conciertos", "Exposiciones artísticas", no tienen ni ojos no oídos para ello. Si alguien construye una marioneta en la que se ve cómo cuelgan los cordones que la mueven, y cuyos brazos y pies crujen a cada paso en yambos de cinco pies. ¡Qué carácter, qué lógica! Si uno coge algo de sentimiento, una sentencia, un concepto, y lo viste de levita y pantalón, le pone manos y pies, le colorea el rostro y deja que esa cosa se arrastre penosamente a lo largo de tres actos hasta que al final se casa o se pega un tiro:

35 Presberg. 1994, op. cit. (Nota 31) p. 60.

36 Büchner, Georg. Obras Completas. Traducción de Carmen Gauger. Madrid: Trotta. 1992, p. 189. 
¡ideal! Si alguien toca mal una ópera que reproduce las depresiones y exaltaciones del alma humana como un silbato de agua reproduce el canto del ruiseñor: ¡oh, el arte! (ach, die Kunst). 37

En su fundamento, la burla de Cervantes o la de Büchner, se basan en una crítica de la mimesis similar a la que veíamos más arriba en Platón. Una mimesis por la que los individuos se observan a sí mismos, alienados y extasiados como Narciso, a través del mono adivino de maese Pedro. ${ }^{38}$ Un mono adivino frente a cuyo espectáculo el espectador debe antes conocerse a sí mismo, como en el oráculo, y no confundirse en la cercanía mimética, «demasiado humana» con él, pues lo hemos reconocido por la levita y los pantalones. Una mimesis que advierte, como Platón, de la manipulación de la realidad mediante la copia artificialmente artística, por la que el individuo masificado se olvida de sí mismo y de la realidad:

Sacad a la gente del teatro y ponedla en la calle. ¡Oh, la triste realidad! Olvidan al Dios Creador a causa de sus malos copistas. De la Creación que, ardiente, impetuosa y brillante, se regenera a cada instante en torno a ellos, ni oyen ni ven nada. Van al teatro, leen poesías y novelas, imitan los visajes de las caretas que allí encuentran y dicen a las criaturas de Dios: ¡qué vulgaridad!39

De este modo, Cervantes, a través del mono adivino, presenta el «arte» del retablo dentro del arte novelesco de don Quijote, el cual tampoco queda especularmente fascinado por el mono adivino. Y es que don Quijote no se diverge a través de la tentación mimética, tan humana, del arte simiescamente adivinatorio. Es por ello que Adorno resaltara el hecho de que el verdadero arte consiste siempre en estar siempre en des-acordarse, esto es, en romper o descolocar. Mientras que divertirse consiste, por el contrario, en estar siempre de acuerdo, 40 como los que se divierten frente al mono, símbolo del arte demasiado miméticamente apropiador. Don Quijote, rompe la tentación del arte simiesco, aunque demasiado humano, rompiendo a su vez esa distancia tan cercana, pues él se sabe a sí mismo. El arte, por contra, y como temió Platón, embelesa narcisistamente en su «demasiado humana» especularidad reflexiva. No obstante, esa reflexividad, como Sócrates intenta mostrar a Alcibíades, no resulta el verdadero autoconocimiento, sino más bien al contrario. Es por ello que en un comentario a esta escena büchneriana, el poeta en len-

\footnotetext{
37 Ibid., 102.

38 Recuérdese de paso que Cervantes dio por título a su primera obra en prosa, escrita en 1585, el título de La Galatea, mismo nombre con el que Pigmalión, otro gran ejemplo de Narciso ante su arte mimético, bautizó a su escultura vivificada.

39 Büchner, 1992, op. cit. (Nota 36), p. 102.

40 Adorno, Theodor W. \& Horkheimer, Max. Dialéctica de la Ilustración. Traducción de Joaquín Chamorro Mielke. Madrid: Akal. 2007, p. 157.
} 
gua alemana P. Celan hable de «un salir de lo humano, un salir a un ámbito dirigido a lo humano e insólito, el mismo en el que la figura del mono, los autómatas y así... ¡ah, también el arte!- parecen estar en su medio». ${ }^{41}$ En el mismo sentido señaló Pascal42 en sus Pensées que, a través del divertissement artístico, absorto frente a una grácil marioneta o a un mono adivino, el hombre rememora su «caída» en la conciencia y la mortalidad. El humano se ha conocido a sí mismo a través de su mimesis en el espejo artístico, pero, según Pascal, al mismo tiempo se ha olvidado de su condición, se ha distraído (di-vertere).

Narciso se contempla en el fluir del río: «empieza la función, el comienzo del comienzo va a dar comienzo inmediatamente!». ${ }^{43} \mathrm{La}$ salida a la artisticidad narcisista es destruida en el caso del Quijote, por un loco que, sin distinguir lo real de lo ficticio, lo verdadero de lo falso, deja sin embargo caer fulminantemente el telón que separa el arte de la realidad, manteniendo su distancia, ni demasiado lejana, ni demasiado cercana. Una distancia que separe lo creatural de lo natural, que funde la significatividad. Así M. Heidegger44 señala que «el mostrar acerca lo mostrado y sin embargo lo mantiene a distancia (...). Cuanto más esencial es la lejanía en que se mantiene ese acercamiento, más cerca está el mostrar de lo mostrado.

Tal y como señala Valeriano Bozal, el arte es siempre una imitación, pero de un modo novedoso. 45 Por ello la mimesis criba, al modo derrideano, en su di-ferida y di-ferente distancia el esteticismo desde los interludios de la incomunicación, desde los desvíos o bucles significativos, desde la desdimensión entre los diversos sistemas sígnicos, desde la realidad y el deseo. Así, para Bozal, «mimesis y representación se identifican justamente en la desapropiación e inconmensurabilidad entre significado y significante». Por ello «la mimesis afirma la identidad en la diferencia». 46

\section{Conclusión}

La mimesis narcisista se dispone por doquier: el ecologismo artistiza la naturaleza como algo prodigado, u otorga derechos humanos a los simios, la diletancia estetiza la Cultura de los museos o los auditorios como templos salvadores pero,diría Büchner- al salir de allí, el sujeto observa y oye a otro sujeto. ¡Qué vulgaridad! Narciso y Eco vuelven al principio: han sido perdonados otra vez.

41 Der Meridian. En Celan, Paul. Gesammelte vol. III. Frankurt a. M: Suhrkamp, 2000, p. 192.

42 Pascal, Blaise. Pensamientos. Traducción de J. Llansó. Madrid. Alianza, 1981, p. 77.

43 Büchner. 1992, op. cit. p. 189.

44 Heidegger, Martin. Interpretaciones sobre la poesía de Hölderlin. Traducción de José María Valverde. Barcelona, Ariel. 1973, p. 157.

45 Bozal, Valeriano. Mimesis. Las imágenes y las cosas. Madrid: Visor. 1987, p. 43.

46 Ibid.. 42 y 70 respect. 
En el filme documental titulado Grizzly Man, el director alemán Werner Herzog nos cuenta la historia real de un joven norteamericano que decide vivir alejado de los hombres para defender a los osos. La vida para él vuelve a tomar la forma de un Paraíso: ha recuperado la inocencia y pureza de los animales frente a la perversión de la sociedad humana. Sin embargo, este nuevo Quijote pretendiente a buen salvaje es devorado finalmente por sus criaturas. Se acercó, al parecer, demasiado a los osos. Así, y al contrario que nuestro hidalgo, el retablo se ha revelado como el Golem ante el ravi Löw, como Frankenstein ante su creador, como Galatea ante Pigmalión. El Paraíso Perdido ha irrumpido. Y sin embargo, algo se ha vuelto a perder. Y es que al contemplar el «arte», el humano se convierte en un Narciso que se apropia de un sí mismo paradisíaco, intemporal y demasiado cercano. Es el segundo término de una metáfora trunca cuyo primer término parece, sin embargo, tan humano.

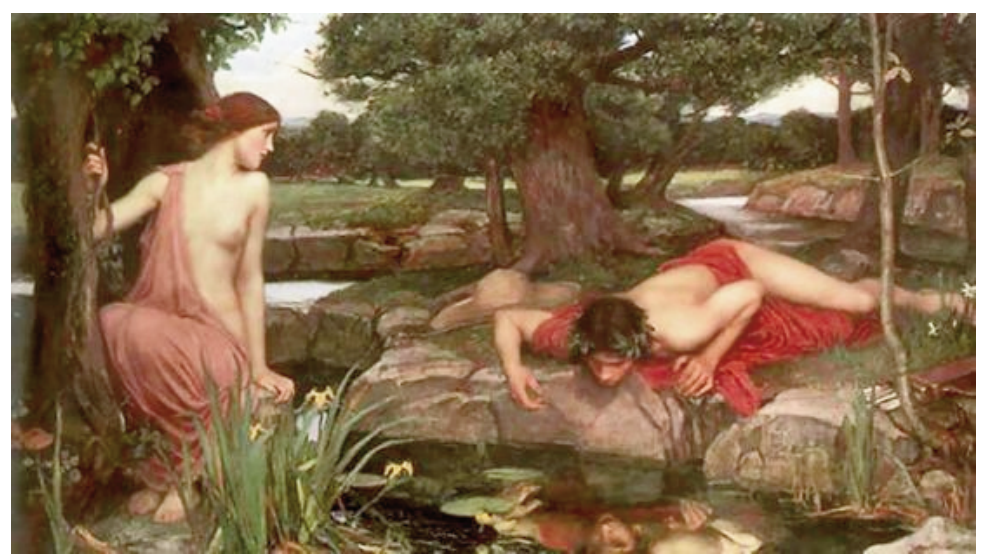

[Eco y Narciso (1905). John William Waterhouse (1849-1917), Walter Art Gallery. Liverpool] 